\title{
Glucosylceramide Critically Contributes to the Host Defense of Cystic Fibrosis Lungs
}

\author{
Barbara Kovacic ${ }^{a}$ Carolin Sehla Barbara Wilker ${ }^{a}$ Markus Kamler ${ }^{\mathrm{b}}$ Erich Gulbins ${ }^{\mathrm{a}, \mathrm{c}}$ \\ Katrin Anne Becker ${ }^{a}$
}

aDepartment of Molecular Biology, University of Duisburg-Essen, Essen, ${ }^{b}$ Department of Thoracic and Cardiovascular Surgery, West German Heart and Vascular Center Essen, University Hospital Essen, Essen, Germany; 'Department of Surgery, University of Cincinnati, Cincinnati, Ohio, USA

\section{Key Words}

Glucosylceramide • Sphingolipids • Cystic fibrosis • Pneumonia • Pseudomonas aeruginosa

\begin{abstract}
Background: Cystic fibrosis (CF) is the most common autosomal-recessive disorder in western countries. Previous studies have demonstrated an important role of sphingolipids in the pathophysiology of cystic fibrosis. It has been shown that ceramide has a central role in various pulmonary infections, including those with Pseudomonas aeruginosa ( $P$. aeruginosa). Ceramide is accumulated in the airways of CF mice and patients. However, little is known about a potential role of glucosylceramide in cystic fibrosis. Methods: We investigated the expression of glucosylceramide and lactosylceramide in the respiratory tract of murine and human CF samples by immunohistochemistry and analyzed effects of glucosylceramide on $P$. aeruginosa in vitro. We performed pulmonary infections with $P$. aeruginosa and tested inhalation with glucosylceramide. Results: We demonstrate that glucosylceramide is down-regulated on the apical surface of bronchial and tracheal epithelial cells in cystic fibrosis mice. Although glucosylceramide did not have a direct bactericidal effect on Pseudomonas aeruginosa in vitro, inhalation of CF mice with glucosylceramide protected these mice from infection with $P$. aeruginosa, while non-inhaled CF mice developed severe pneumonia. Conclusion: Our data suggest that glucosylceramide acts in vivo in concert with ceramide and sphingosine to determine the pulmonary defense against $P$. aeruginosa.

\section{Introduction}

Cystic fibrosis (CF) is one of the most common autosomal recessive disorders in Western populations, constituting one case per 2,500 births, and is caused by mutations of the cystic fibrosis transmembrane conductance regulator gene (CFTR) [1, 2, 3]. Genetic defects of the CFTR molecule cause several clinical symptoms due to a dysfunctional chloride secretion in epithelial cell layers, which in particular involves pulmonary and gastrointestinal organ 


\section{Cellular Physiology Cell Physiol Biochem 2017;41:1208-1218 \\ \begin{tabular}{l|l} 
and Biochemistry Published onIIne: VIarch 06, 2017 & $\begin{array}{l}\text { (c) 2017 The Author(s). Published by S. Karger AG, Basel } \\
\text { www.karger.com/cpb }\end{array}$ \\
\hline
\end{tabular} \\ Kovacic et al.: Glucosylceramide in Cystic Fibrosis}

systems. Although the gastrointestinal problems include destruction of pancreatic tissue and alterations of the liver, which leads to a lack of secretion of pancreatic enzymes and biliary cirrhosis, they can usually be controlled $[4,5]$. Pulmonary problems are the major cause of morbidity and they determine the quality of life and the life expectancy of CF patients [5].

Chronic inflammation is one of the most important pulmonary problems of $\mathrm{CF}$ patients because it causes lung destruction. In addition, patients suffer from increased susceptibility to infections with pathogens such as Pseudomonas aeruginosa (P. aeruginosa) and Staphylococcus aureus (S. aureus), Burkholderia cepacia and Haemophilus influenza [6]. The molecular mechanisms that lead to chronic inflammation and high susceptibility to pulmonary infections are still not completely determined, but may include abnormal activation of transcription factors [7], accumulation of lipids [8, 9], ER-stress [10] or altered autophagy [11], to name a few potential mechanisms.

Chronic pulmonary infection with $P$. aeruginosa is a common cause of morbidity and mortality as more than $70 \%$ of adult CF patients are infected with this pathogen [12]. Furthermore, efficient treatment of pulmonary infections has become more challenging since injudicious use of prescribed antibiotics led to progressive development of resistant strains [13]. Therefore, it is very important to identify molecular mechanisms involved in P. aeruginosa infections in CF patients to develop novel treatments.

Sphingolipids play an important role in innate immunity and in the pathogenesis of increased infection susceptibility and inflammation in CF, which makes them potential targets for new treatments of CF [8, 14-17]. They are composed of a hydrophobic ceramide moiety and a hydrophilic headgroup, and are major components, together with cholesterol and glycerolipids, of mammalian cell membranes [18, 19].

Ceramide, which is an amide ester of D-erythro-sphingosine and a fatty acid containing 2-32 carbon atoms in the acyl chain, can be generated through various pathways including the de novo synthase and the metabolic pathway [19-21]. The generation of ceramide within membranes has the potential to significantly change membrane properties, as ceramide molecules tend to bind strongly to each other by hydrophobic interactions $[18,19]$. This self-association of ceramide molecules leads to a formation of small ceramide-enriched membrane domains, which spontaneously fuse into large ceramide-enriched membrane platforms $[22,23]$. It has been demonstrated that these domains serve to trap, cluster and (re-)organize receptor and intracellular signaling molecules in the cell membrane [22, 24, 25]. Formation of ceramide-enriched membrane domains is triggered by several receptors, stress stimuli and pathogens including P. aeruginosa [24]. Further studies showed that ceramide has a critical role in the host response to P. aeruginosa [26] and in the development of CF [8]. Different Cftr-deficient mice strains showed an accumulation of ceramide in lungs, in particular in epithelial cells of bronchi and alveolar macrophages, even prior to any infection [8]. Ciliated nasal epithelial cells and lung specimens from transplant material from patients with CF also showed an accumulation of ceramide [8, 15, 27].

Recent studies demonstrated that a degradation product of ceramide, the sphingoid long chain base sphingosine, has an important role in the defense against $P$. aeruginosa [17]. These studies demonstrated that sphingosine levels are significantly reduced in the bronchial and tracheal epithelial cells of CF patients and mice. Inhalation of $C f t r$-deficient mice with sphingosine or acid ceramidase, which hydrolyses ceramide to sphingosine, restored sphingosine levels on the surface of airway epithelial cells and prevented $P$. aeruginosa infections in these mice. These findings indicate that the constitutive presence of sphingosine in healthy upper airway epithelial cells serves to kill pathogens [17]. This hypothesis would explain how healthy upper airways, which are constantly exposed to pathogens, usually eliminate these pathogens, including P. aeruginosa, without any signs of inflammation.

Another class of sphingolipids, i.e. glycosphingolipids, also has a role in P. aeruginosa infections. Glycosphingolipids are composed of a ceramide backbone, which varies in length, hydroxylation, and saturation of both the sphingosine and fatty acid moieties, resulting in lipid structural diversity that impacts the presentation of the attached glycan at membrane 
surfaces [28-30]. In higher animals the first sugars linked to ceramide are $\beta$-linked galactose (GalCer) or glucose (GlcCer) after which numerous other carbohydrates can be attached [29].

Despite the fact, that expression of the glycosylsphingolipids GM-1 and asialo-GM-1 is altered in CF respiratory epithelial cells [31,32], recent studies revealed that glucosylceramide (GlcCer), one of the simplest glycosphingolipids, may play a role in P. aeruginosa infections $[33,34]$. Studies employing miglustat, an inhibitor of two different GlcCer degrading enzymes, glucocerebrosidase (GBA1) and non-lysosomal $\beta$-glucosidase 2 (GBA2), showed that this inhibitor reduces levels of ceramide induced by $P$. aeruginosa infection [33]. It has been demonstrated that GBA1 and GBA2 activities are elevated in CF bronchial cell during $P$. aeruginosa infection [34]. IL-8 mRNA expression and protein release stimulated by $P$. aeruginosa in CF bronchial cells were reduced when GBA2 expression and function were decreased [34]. Furthermore, significant ceramide reduction was observed after the addition of the specific inhibitor of GBA2, Genz-529648, in CF bronchial cells infected with $P$. aeruginosa, which strongly suggests that GBA2 is directly involved in ceramide formation after P. aeruginosa infection [34].

To gain further insights into the molecular mechanisms of pulmonary P. aeruginosa infections and the role of sphingolipids during infection, we explored the potential involvement of glucosylceramide, alone and combined with sphingosine, in $P$. aeruginosa infections in CF. The expression of LacCer and GlcCer was examined in respiratory airways of $C f t$-deficient mice and the effect of GlcCer in vitro on two different strains of $P$. aeruginosa was tested. Our studies demonstrate that GlcCer is down-regulated in airway epithelial cells of $C f t r$-deficient mice. Inhalation of $C f t r$-deficient mice with GlcCer protected these mice from infection with $P$. aeruginosa, compared to non-inhaled $C f t r$-deficient mice. These data indicate an important role of GlcCer in the pulmonary defense against $P$. aeruginosa.

\section{Materials and Methods}

Mice

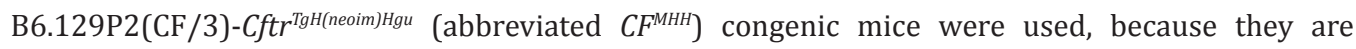
developing cystic fibrosis in the lungs without manifesting gastrointestinal symptoms due to low expression of Cftr in the intestine [35]. They were generated by brother-sister mating from the original CftrigH(neoim) Hgu mutant mouse and then backcrossed into the B6 inbred background. Original CftrigH(neoim)Hgu mice were generated by insertional mutagenesis in exon 10 of the $C f t r$ gene [36]. Syngenic B6 mice served as controls. All mice were bred and housed in the special pathogen free facility of the University Hospital, University of Duisburg-Essen, Essen, Germany. Mice were handled according to international guidelines and protocols approved by the Animal Care Committee (Az 84-02.04.2013.A282). To ensure full manifestation of CF disease, mice were used between 14-24 weeks of age.

\section{Human samples}

Punch biopsies of human lungs from CF patients and corresponding organ donors were performed at the Department of Thoracic Transplantation, West German Heart and Vascular Center, University Hospital Essen (Germany). Lung biopsies were fixed in 4\% paraformaldehyde (PFA) for $36 \mathrm{hrs}$ and then embedded in paraffin.

The study was approved by the local ethics committee, all patients gave informed consent.

\section{Bacteria}

P. aeruginosa strains 762 and ATCC 27853 were seeded on fresh tryptic soy agar (TSA) plates (Becton Dickinson Biosciences, Heidelberg, Germany) and incubated overnight at $37^{\circ} \mathrm{C}$. The next day, bacteria were transferred into $40 \mathrm{~mL}$ of pre-warmed, sterile tryptic soy broth (TSB, Becton Dickinson Biosciences) in Erlenmeyer flask. To obtain bacteria in the early logarithmic phase, the optical density at $550 \mathrm{~nm}$ was set to 0.225 , and bacteria were incubated for $1 \mathrm{~h}$ at $37^{\circ} \mathrm{C}$ on a horizontal shaker $(125 \mathrm{rpm})$. After incubation, bacteria were pelleted by centrifugation (10 $\mathrm{min}, 1,710 \mathrm{xg}$ ), resuspended and diluted as indicated below. 


\section{Cellular Physiology Cell Physiol Biochem 2017;41:1208-1218 \begin{tabular}{l|l|l} 
and Biochemistry Published onIIne: IVIarch 06, 2017 & $\begin{array}{l}\text { (c) } 2017 \text { The Author(s). Published by S. Karger AG, Basel } \\
\text { www.karger.com/cpb }\end{array}$
\end{tabular} \\ Kovacic et al.: Glucosylceramide in Cystic Fibrosis}

\section{In vitro treatment of bacteria}

After centrifugation, P. aeruginosa strains 762 and ATCC 27853 were washed twice with $10 \mathrm{~mL}$ sterile phosphate buffered saline (PBS, $137 \mathrm{mM} \mathrm{NaCl}, 10.2 \mathrm{mM} \mathrm{Na}_{2} \mathrm{HPO}_{4}, 2.7 \mathrm{mM} \mathrm{KCl}$, and $1.7 \mathrm{mM} \mathrm{KH}_{2} \mathrm{PO}_{4}, \mathrm{pH}$ 7.3), and resuspended in PBS to a concentration of $1 \times 10^{3}$ colony forming units (CFU)/mL. Stock solutions of C16 $\beta$-D-glucosylceramide and D-erythro-sphingosine (Avanti Polar Lipids, Inc., Alabama, USA, 860539P and 860490P, respectively) were dissolved in 10\% n-octyl- $\beta$-D-glucopyranoside (OGP, Sigma-Aldrich, Steinheim, Germany) in a concentration range from $50 \mu \mathrm{M}$ to $2 \mathrm{mM}$ and bath-sonicated for 10 minutes, if indicated combined and sonicated again. $10 \mu \mathrm{l}$ of sphingolipids were added to $1 \mathrm{~mL}$ bacterial solution and bacteria were incubated for $1 \mathrm{~h}$ at $37^{\circ} \mathrm{C}$ on a horizontal shaker $(125 \mathrm{rpm}) .200 \mu \mathrm{L}$ of a bacteria solution were directly plated on LB agar plates, incubated for $14 \mathrm{hrs}$ at $37^{\circ} \mathrm{C}$ and bacterial CFU were counted.

\section{Infection of mice}

For mouse infections studies, P. aeruginosa strain 762 was directly resuspended in pre-warmed HEPES/Saline buffer (H/S, $132 \mathrm{mM} \mathrm{NaCl}, 20 \mathrm{mM}$ HEPES, $5 \mathrm{mM} \mathrm{KCl}, 1 \mathrm{mM} \mathrm{CaCl}, 0.8 \mathrm{mM} \mathrm{MgSO}{ }_{4}, 0.7 \mathrm{mM}$ $\mathrm{MgCl}_{2}, \mathrm{pH}$ 7.4).

Mice were anesthetized for 10-15 seconds with ether and infected by an intranasal injection of $5 \times 10^{7}$ CFU in $20 \mu \mathrm{L} \mathrm{H} / \mathrm{S}$. A 30-gauge 1-mL syringe was used to perform nasal injections and the needle was covered with a tightly fitting, smooth plastic tube so that any nasal injuries were avoided.

Mice were infected and sacrificed by cervical dislocation 2 hrs after infection. Lungs were immediately removed under sterile conditions, homogenized and lysed in $5 \mathrm{mg} / \mathrm{mL}$ saponin for 10 minutes at $37^{\circ} \mathrm{C}$ to release intracellular bacteria. RPMI-1640 medium (Gibco/Invitrogen, Karlsruhe, Germany) supplemented with $10 \mathrm{mM}$ HEPES was added, samples were centrifuged for 10 minutes at 2,240×g and resuspended in RPMI-1640 medium/10 mM HEPES. Aliquots were plated on TSA plates and after overnight growth bacteria colonies were counted.

\section{Mouse inhalation}

Mice were inhaled 45-60 minutes prior to infection using a PARI Boy SX nebulizer (PARI GmbH, Starnberg, Germany) through a mask, which is part of an oral inhalation device for children (LL-Nebulizer) and was clipped at the sides to cover only the nose and the surrounding part of the face. Mice inhaled 800 $\mu \mathrm{L}$ of $0.9 \% \mathrm{NaCl}$ containing $125 \mu \mathrm{M}$ C16 $\beta$-D-glucosylceramide (Avanti Polar Lipids, Inc., Alabama, USA), that was bath-sonicated 10 minutes directly before use.

\section{Immunostainings}

Mice were sacrificed, lungs or trachea instantly removed and fixed for $36 \mathrm{hrs}$ in 4\% PFA buffered in PBS.

Mouse and human samples were then dehydrated using increasing (70\%-100\%) ethanol concentrations and Xylol (PanReac AppliChem), embedded in paraffin, cut in $6 \mu \mathrm{m}$ thin sections and left in an incubator at $50^{\circ} \mathrm{C}$ for overnight drying.

Sections were dewaxed using Xylol, and rehydrated by incubation in ethanol with decreasing $(100 \%$ to $70 \%$ ) concentrations and Millipore-water. Afterwards, sections were incubated with Pepsin Digest All (Invitrogen Life Technologies, USA) for 30 minutes at $37^{\circ} \mathrm{C}$, washed with distilled water, and blocked for 15 minutes with PBS $+0.05 \%$ Tween $20+5 \%$ fetal calf serum (FCS). They were then incubated with polyclonal antibodies directed against glucosylceramide (diluted 1:200, Glycobiotech, Germany, RAS_0010) or lactosylceramide (diluted 1:200, Glycobiotech, Germany, MAS_0090) for 45 minutes. Both antibodies were diluted in H/S plus 1\% FCS. Sections were washed three times in PBS plus 0.05\% Tween 20, incubated with a Cy3-coupled donkey anti-rabbit IgG (diluted 1:1000, Jackson ImmunoResearch Laboratories, Inc., Pennsylvania, USA, 711-166-152) or a Cy3-coupled donkey anti-mouse IgG (diluted 1:1000, Jackson ImmunoResearch, 715-166-150), washed three times in PBS plus 0.05\% Tween 20 and once in PBS, and embedded in Mowiol. Samples were analyzed by confocal microscopy on a Leica TCS SP5 microscope.

\section{Statistics}

Data are expressed as mean \pm SD. Statistical significance was evaluated using the GraphPad Prism 5 program. Data were analyzed using ANOVA with Bonferroni as post-hoc test for multiple comparisons. A p-value of 0.05 or less was considered significant. 


\section{Cellular Physiology Cell Physiol Biochem 2017;41:1208-1218

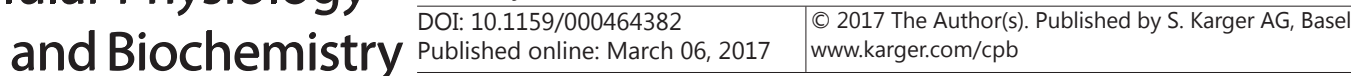

\section{Results}

Glycosylsphingolipids in the respiratory tract

Numerous studies have shown that expression of ceramide and sphingosine is altered in the respiratory tract of cystic fibrosis patients and mice and that both sphingolipids have an important role in P. aeruginosa infections [8, 14, 17, 37]. Based on these findings, we aimed to determine if there is a difference in expression of the glycosphingolipids glucosylceramide (GlcCer) and lactosylceramide (LacCer) in the respiratory tract between wild type (WT) and CF mice. Immunohistochemical staining with a glucosylceramide-specific antibody showed higher expression of GlcCer on the apical surface of bronchial and tracheal epithelial cells in wild type mice than in CF mice (Fig. 1A). There was no difference in expression of LacCer in epithelial cells of the respiratory tract between CF and WT mice (Fig. 1B). In addition, we analyzed GlcCer expression in human lung samples from CF patients and organ donors. Apical membranes of bronchial cells received from healthy donors showed bright levels for GlcCer, while the staining was much weaker in corresponding areas in CF lungs (Fig. 2A+B).

These results demonstrate that levels of glucosylceramide are reduced in the respiratory tract of CF patients and mice.

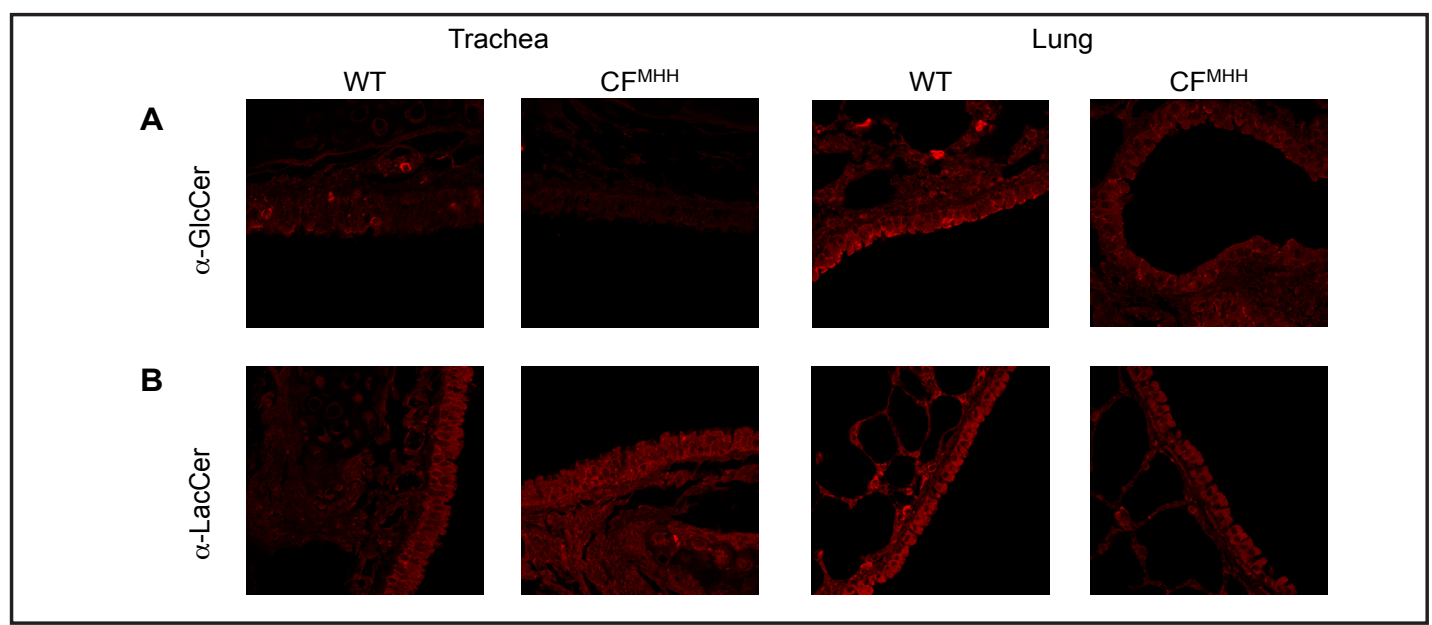

Fig. 1. Immunohistochemical analysis of glycosphingolipids in airways of wildtype (WT) and cystic fibrosis (CF) mice. Immunohistochemical stainings of murine trachea and lung tissue obtained from WT and CF mice using anti-GlcCer- (A) and anti-LacCer- (B) antibodies. Samples were analyzed by confocal microscopy using a $100 \mathrm{x}$ object lens. Shown are representative images from 5 mice.

Fig. 2. Immunohistochemical analysis of glucosylceramide in human lungs. Human lung biopsies were stained with anti-GlcCer-antibody (A, B). Panel B shows a magnification of an area of interest from panel A. Samples were analyzed by confocal microscopy with a $63 x$ objective. Shown are representative images from 3 human lungs.

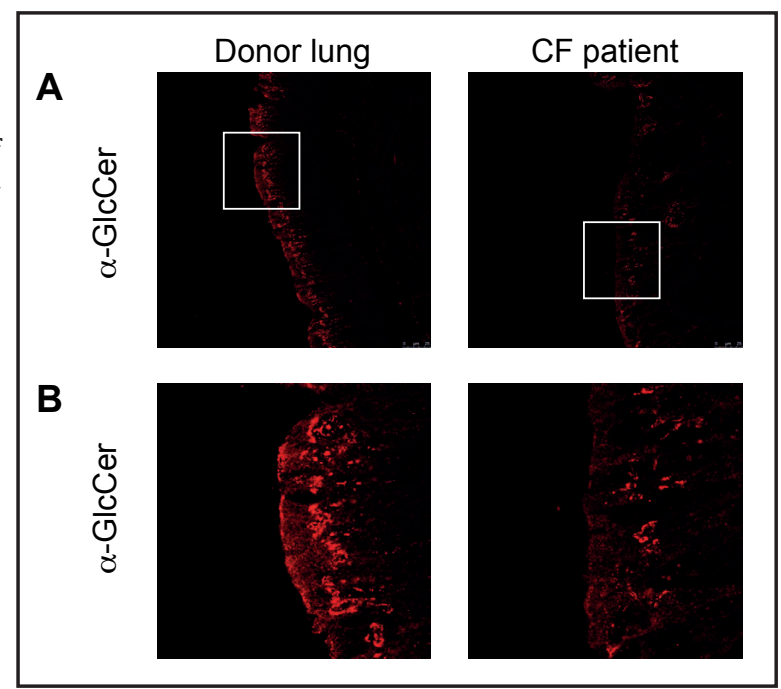




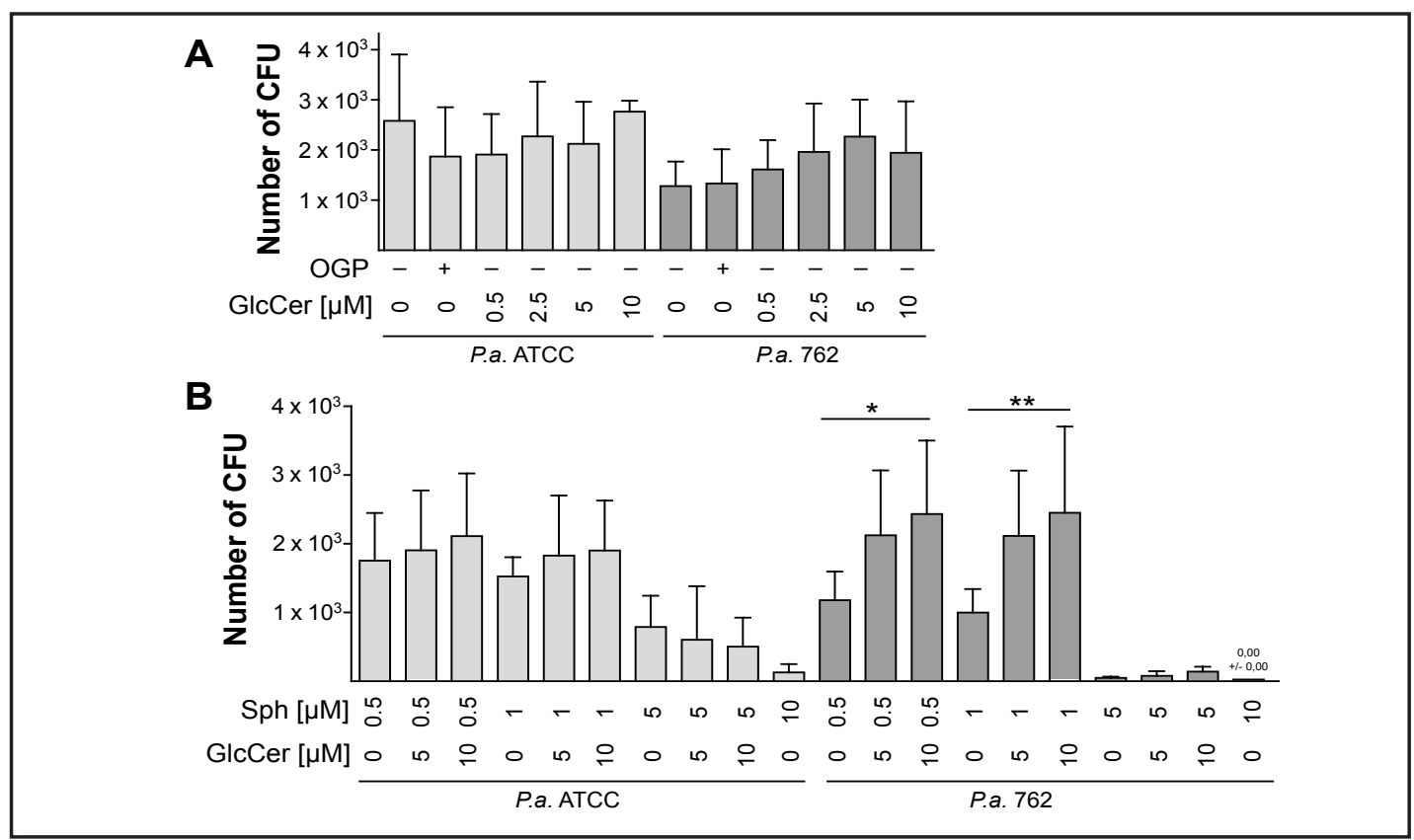

Fig. 3. Incubation of $P$. aeruginosa strains 762 and ATCC 27853 with $\beta$-glucosylceramide and sphingosine. Bacteria were incubated for $1 \mathrm{~h}$ with $\beta$-GlcCer, sphingosine (Sph) or a combination of both in PBS and 20\% of the suspension was plated on agar plates, incubated at $37^{\circ} \mathrm{C}$ overnight and CFU were counted the day after. Bacterial growth was compared within groups received same Sph concentrations. Shown are the mean $\pm \mathrm{SD}, \mathrm{n} \geq 5,{ }^{*} \mathrm{p}<0.05,{ }^{* *} \mathrm{p}<0.01$, ANOVA and Bonferroni post-hoc test.

Glucosylceramide effects on different P. aeruginosa stains

Since levels of sphingosine are also reduced in CF and this sphingolipid acts bactericidal, we hypothesized that GlcCer may also inhibit bacterial growth and that a combination of GlcCer and sphingosine may synergistically impede P. aeruginosa growth.

We tested this hypothesis by incubation of the P. aeruginosa strains 762 and ATCC 27853 in vitro with sphingosine, $\beta$-glucosylceramide or their combination in PBS. The results showed that $\beta$-GlcCer alone has no significant effect on growth of $P$. aeruginosa strain ATCC 28753 or 762 (Fig. 3A). In contrast, sphingosine killed the different $P$. aeruginosa strains at low micromolar concentrations. However, a combination of sphingosine and GlcCer did not increase the effect of sphingosine (Fig. 3B). For P. aeruginosa strain 762, the combinations of $10 \mu \mathrm{M}$ GlcCer with $0.5 \mu \mathrm{M}$ and $1 \mu \mathrm{M}$ sphingosine even promoted growth of bacteria when compared to corresponding concentrations of sphingosine alone. Most likely, the bacteria use GlcCer as carbon source and therefore growth is promoted.

These results showed that $\beta$-GlcCer and sphingosine do not synergistically inhibit growth of $P$. aeruginosa in vitro. In fact, at certain ratios of $\beta$-GlcCer and sphingosine, $\beta$-GlcCer even inhibited the bactericidal effect of sphingosine in vitro.

Inhalation of $\beta$-glucosylceramide prevents in vivo infection with P. aeruginosa

To unambiguously analyze the function of GlcCer in the airways of CF mice during infection, we performed in vivo infection experiments. To this end, we inhaled CF mice with $\beta$-GlcCer prior to infection with P. aeruginosa 762. Non-inhaled CF and WT mice were also infected with $P$. aeruginosa and served as controls. Non-inhaled CF mice rapidly succumbed to infection and showed signs of severe pneumonia 2 hrs after intranasal injection of $5 \mathrm{x}$ $10^{7}$ CFU of $P$. aeruginosa 762, while WT and CF mice inhaled with $\beta$-GlcCer showed no or only mild signs of infection by that time. All mice were sacrificed 2 hrs after infection and lungs were removed for analyses of CFU. The short time course allows analyzing the role of $\beta$-GlcCer in the acute phase of a pulmonary infection. The results revealed that lungs of 
Fig. 4. Inhalation of $\beta$-glucosylceramide prevents in vivo infection with $P$. aeruginosa. Inhalation of $\beta$-GlcCer significantly reduced the number of bacteria in cystic fibrosis (CF) lungs (A) and elevated levels of GlcCer in apical membrane of CF bronchial epithelial cells (B). CF mice were inhaled with $\beta$-GlcCer 30 min prior to infection with $P$. aeruginosa. Infection was compared to that in non-inhaled $\mathrm{CF}$ and of WT mice. The bacterial load of lungs was determined 2 hrs after infection of the mice. Displayed are means \pm $\mathrm{SD}, \mathrm{n} \geq 3,{ }^{* * *} \mathrm{p}<0.001$, ANOVA and Bonferroni post-hoc test (A). Sections of lungs of a different set of mice that were sacrificed 30 min after inhalation of $\beta$-GlcCer were stained with anti-GlcCer (B).

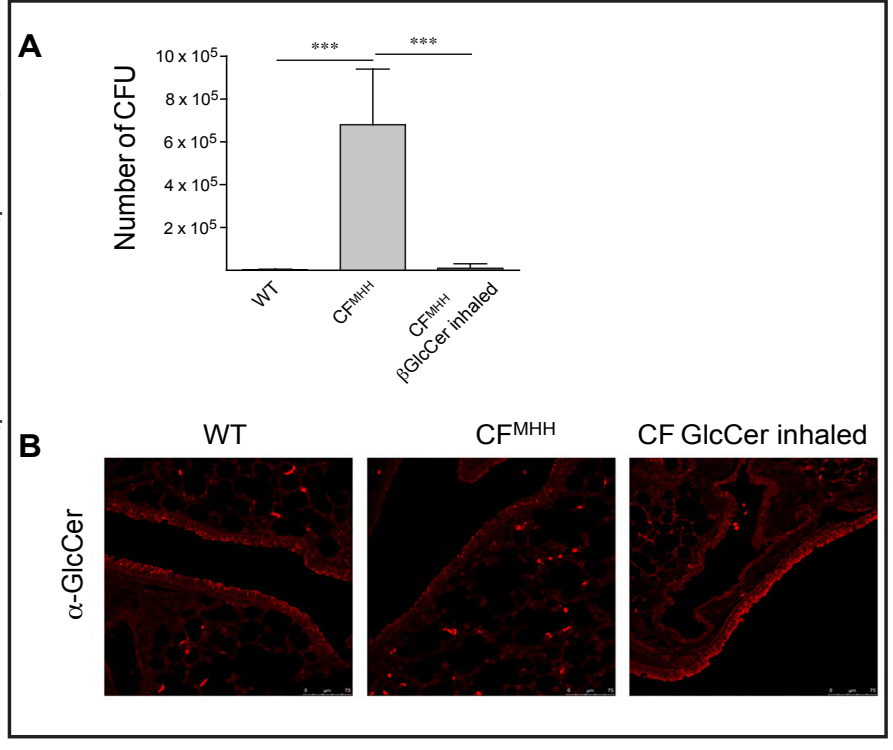

$\beta$-GlcCer inhaled CF mice contained significantly less bacteria than non-inhaled CF mice (Fig. $4 \mathrm{~A}$ ). Inhalation of $\beta$-GlcCer reduced the infection in CF mice to the low levels in WT mice, which are largely resistant to the infection with P. aeruginosa (Fig. 4A). To determine if levels of glucosylceramide are altered in the epithelial cells of the lungs after inhalation, we inhaled $\mathrm{CF}$ mice with $\beta$-GlcCer, sacrificed those $30 \mathrm{~min}$ after inhalation, removed the lungs, fixed and embedded them in paraffin. Sections of WT, CF and CF mice inhaled with $\beta$-GlcCer were stained with anti-GlcCer antibody. Immunohistochemical stainings showed an increase of GlcCer levels in the apical membranes of bronchial epithelial cells in CF mice after inhalation (Fig. 4B).

These results demonstrate that inhalation of $\beta$-GlcCer in vivo supports the innate immune system to kill $P$. aeruginosa and, thereby, has a positive effect on survival of CF mice infected with $P$. aeruginosa strain 762.

\section{Discussion}

While the effects of ceramide and sphingosine in P. aeruginosa infections in cystic fibrosis have been well demonstrated [8, 14, 17, 37], little is known about an effect of glycosphingolipids. Here, we demonstrate that levels of GlcCer are lower on the apical surface of tracheal and bronchial epithelial cells of CF mice than in WT mice. Inhalation of $\beta$-GlcCer prevented the development of severe pneumonia in CF mice and allowed the mice to kill the pathogen after intranasal infection of CF mice. This indicates that $\beta$-GlcCer contributes to the defense of the airways against $P$. aeruginosa. In contrast, we did not detect any differences in expression of lactosylceramide in the respiratory tract between CF and WT mice.

It has been shown that sphingosine levels are reduced in epithelial cells of the airways of CF mice and that sphingosine kills P. aeruginosa and S. aureus, but also other pathogens, in vitro and in vivo [17,37]. Since levels of GlcCer are also reduced in CF, we hypothesised that GlcCer may also act bactericidal in vitro and that a combination of GlcCer and sphingosine may synergistically inhibit $P$. aeruginosa growth. However, the results showed that GlcCer alone has no significant growth inhibiting effect on both P. aeruginosa strain ATCC 28753 and 762. Furthermore, a combination of sphingosine and GlcCer did not show significantly better inhibition of bacterial growth than sphingosine alone. For the P. aeruginosa strain 762 combinations of $10 \mu \mathrm{M}$ GlcCer even reduced the bactericidal effect of 0.5 and $1 \mu \mathrm{M}$ sphingosine. Most likely, the bacteria use GlcCer as carbon source in vitro and therefore growth is promoted.

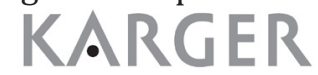


To analyze the function of GlcCer in the airways of CF mice, we performed in vivo experiments and inhaled CF mice with GlcCer prior to infection with P. aeruginosa strain 762. The inhalation of GlcCer greatly promoted elimination of the bacteria from the airways of CF mice and thereby the survival of infected CF mice. At present, it is unknown how GlcCer prevents infection of CF mice with $P$. aeruginosa. In contrast to sphingosine, GlcCer does not directly kill bacteria. It might be possible that GlcCer interferes with ceramide and in particular ceramide-enriched membrane platforms. Ceramide is greatly increased in CF airways and increased ceramide concentrations were previously linked to the induction of epithelial cell death in CF airways, which in turn results in release of DNA into the airways [8]. DNA in the airways seems to be a critical component of the infection process in CF mice, since we have shown that inhalation with DNase also prevents infection of CF mice with $P$. aeruginosa [8]. In this scenario, sphingosine provides the normal defense barrier in the upper airways against pathogens. In the absence of sphingosine, as in CF, bacteria reach the lung, but are only able to colonize the lung and induce pneumonia, if further defense mechanisms fail and/or the conditions for growth, such as the presence of free DNA as in CF lungs, are provided. Thus, although not proven, GlcCer may prevent clustering of CD95 in ceramide-enriched membrane domains that has been previously shown to initiate epithelial cell death in CF $[22,38]$. By an interference with ceramide-enriched membrane platforms and proteins that cluster within these domains in CF airway epithelial cells, GlcCer might prevent signaling via these platforms and thereby induction of inflammation and cell death. The increase of GlcCer after inhalation would then prove beneficial in CF by preventing these pathologies resulting in the observed protection of CF mice from P. aeruginosa infection.

A beneficial role of GlcCer in CF is also supported by recent findings, which demonstrated that inhibitors of GBA2, the enzyme that degrades GlcCer into ceramide, had a positive effect on the inflammatory response of CF cells induced by P. aeruginosa infection [34]. Inhibition of GBA2 resulted in a concomitant reduction in IL-8 levels and to a significant decrease of the ceramide content in CF bronchial cells infected with P. aeruginosa [34]. Whether levels of GlcCer were also upregulated in epithelial cells upon application of the inhibitor has not been investigated in this study. This and our study indicate an important role of GlcCer in the pulmonary defense against $P$. aeruginosa. The GBA2 inhibitor miglustat, which was used by Loberto and colleagues [34], shows good oral bioavailability and is used as drug in Europe and USA [39]. In addition, miglustat can restore the activity of chloride channels in F508delCFTR respiratory and pancreatic cells [40]. However, a clinical study, recently performed as proof-of-concept study [41], failed to show a significant change in total chloride secretion assessed by nasal potential difference and sweat chloride values as well as of the forced expiratory volume (FEV1) after 8 days of miglustat administration. Further studies in CF patients are necessary to prove whether miglustat has a beneficial effect on pulmonary infections with $P$. aeruginosa.

Since GlcCer can be easily administrated via inhalation as an aerosol or as dry substance, our findings hypothesize GlcCer as promising treatment in patients suffering from cystic fibrosis. Given that ceramide also plays a very critical role in cystic fibrosis and normalization of ceramide levels by blockers of the acid sphingomyelinase has been shown to prevent infection and inflammation in cystic fibrosis patients [42-44], we hypothesize that a therapy that combines normalization of ceramide levels with inhalation of glucosylceramide and/ or sphingosine $[17,37]$ might be the most promising way preventing or treating existing bacterial infection in CF patients in the future. Since other drugs, like antibiotics, can also be applied via an inhalation therapy in CF [45], this way of application offers the benefits of a local administration with minimal adverse systemic effects. It has to be proved if administration of GBA2 inhibitors can also be applied via inhalation and if a combination therapy of ceramide reducing and GlcCer stabilizing/generating strategy is more promising than application of one drug alone.

In summary, we demonstrate that GlcCer is downregulated on the apical surface of bronchial and tracheal epithelial cells in CF mice. Inhalation of CF mice with GlcCer protected 


\section{Cellular Physiology Cell Physiol Biochem 2017;41:1208-1218

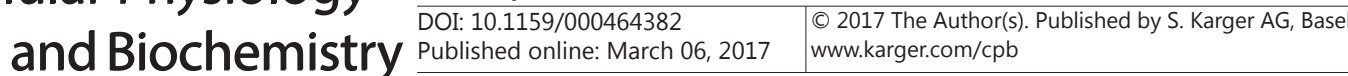

Fig. 5. Graphical summary. Imbalance between sphingolipids ceramide (increased) on the one hand and sphingosine and glucosylceramide (decreased) on the other hand contributes to the high susceptibility of CF mice and patients to bacterial pulmonary infections. Inhalation of C16-glucosylceramide corrects this hypersusceptibility to $P$. aeruginosa of $\mathrm{CF}$ mice.

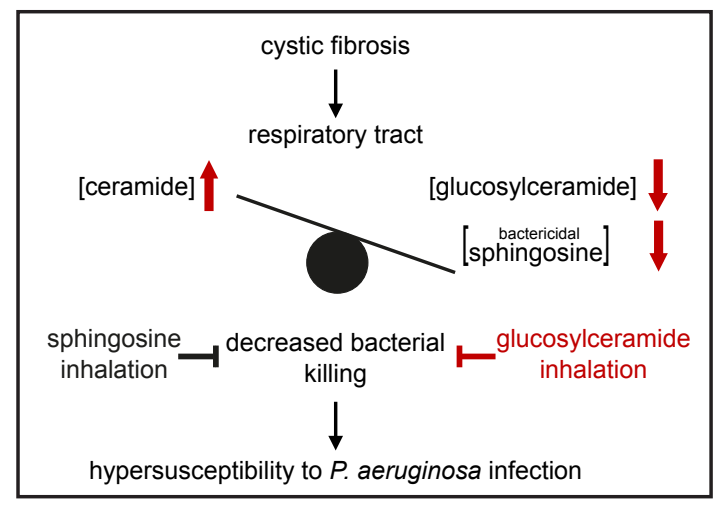

these mice from infection with P. aeruginosa, while non-inhaled CF mice developed severe pneumonia (Fig. 5).

\section{Acknowledgements}

The study was supported by DFG grants GU335/35-1 to EG and GRK 2098 to KAB and EG, NIH 2 R01 HL075 316-09 and MRC subgrant MR/M008797/1 to EG.

\section{Disclosure Statement}

The authors have nothing to disclose.

\section{References}

1 Kerem B, Rommens JM, Buchanan JA, Markiewicz D, Cox TK, Chakravarti A, Buchwald M, Tsui LC: Identification of the cystic fibrosis gene: genetic analysis. Science 1989;245:1073-1080.

2 Rommens JM, Iannuzzi MC, Kerem B, Drumm ML, Melmer G, Dean M, Rozmahel R, Cole JL, Kennedy D, Hidaka N, Zsiga M, Buchwald M, Riordan JR, Tsui LC, Collins FS: Identification of the cystic fibrosis gene: chromosome walking and jumping. Science 1989;245:1059-1065.

-3 Ehrhardt A, Chung WJ, Pyle LC, Wang W, Nowotarski K, Mulvihill CM, Ramjeesingh M, Hong J, Velu SE, Lewis HA, Atwell S, Aller S, Bear CE, Lukacs GL, Kirk KL, Sorscher EJ. Channel Gating Regulation by the Cystic Fibrosis Transmembrane Conductance Regulator (CFTR) First Cytosolic Loop. J Biol Chem 2016;291:18541865.

4 Durie PR, Kent G, Phillips MJ, Ackerley CA: Characteristic multiorgan pathology of cystic fibrosis in a longliving cystic fibrosis transmembrane regulator knockout murine model. Am J Pathol 2004;164:1481-1493.

-5 Grassmé H, Riethmüller J, Gulbins E: Ceramide in cystic fibrosis. Handb Exp Pharmacol 2013:265-274.

6 Homepage American Cystic Fibrosis Foundation: https://www.cff.org

-7 Wang H, Cebotaru L, Lee HW, Yang Q, Pollard BS, Pollard HB, Guggino WB. CFTR Controls the Activity of NF$\kappa B$ by Enhancing the Degradation of TRADD. Cell Physiol Biochem 2016;40:1063-1078.

-8 Teichgräber V, Ulrich M, Endlich N, Riethmüller J, Wilker B, De Oliveira-Munding CC, van Heeckeren AM, Barr ML, von Kürthy G, Schmid KW, Weller M, Tümmler B, Lang F, Grassmé H, Döring G, Gulbins E: Ceramide accumulation mediates inflammation, cell death and infection susceptibility in cystic fibrosis. Nat Med 2008;14:382-391.

99 Grothe J, Riethmüller J, Tschürtz SM, Raith M, Pynn CJ, Stoll D, Bernhard W. Plasma phosphatidylcholine alterations in cystic fibrosis patients: impaired metabolism and correlation with lung function and inflammation. Cell Physiol Biochem 2015;35:1437-1453. 


\section{Cellular Physiology Cell Physiol Biochem 2017;41:1208-1218 \begin{tabular}{l|l|l} 
and Biochemistry Publisned onIIne: IVIarch 06, 2017 & $\begin{array}{l}\text { (c) } 2017 \text { The Author(s). Published by S. Karger AG, Basel } \\
\text { www.karger.com/cpb }\end{array}$
\end{tabular} \\ Kovacic et al.: Glucosylceramide in Cystic Fibrosis}

10 Bartoszewski R, Rab A, Jurkuvenaite A, Mazur M, Wakefield J, Collawn JF, Bebok Z. Activation of the unfolded protein response by deltaF508 CFTR. Am J Respir Cell Mol Biol 2008;39:448-457.

11 Luciani A, Villella VR, Esposito S, Brunetti-Pierri N, Medina D, Settembre C, Gavina M, Pulze L, Giardino I, Pettoello-Mantovani M, D'Apolito M, Guido S, Masliah E, Spencer B, Quaratino S, Raia V, Ballabio A, Maiuri L. Defective CFTR induces aggresome formation and lung inflammation in cystic fibrosis through ROSmediated autophagy inhibition. Nat Cell Biol 2010;12:863-875.

12 American Cystic Fibrosis Foundation: Patient Registry Annual Data Report 2014. 2015

13 López-Causapé C, Rojo-Molinero E, Macià MD, Oliver A: The problems of antibiotic resistance in cystic fibrosis and solutions. Expert rev Respir Med 2015;9:73-88.

14 Becker KA, Tümmler B, Gulbins E, Grassmé H: Accumulation of ceramide in the trachea and intestine of cystic fibrosis mice causes inflammation and cell death. Biochem Biophys Res Commun 2010;403:368-374.

15 Brodlie M, McKean MC, Johnson GE, Gray J, Fisher AJ, Corris PA, Lordan JL, Ward C: Ceramide is increased in the lower airway epithelium of people with advanced cystic fibrosis lung disease. Am J Respir Crit Care Med 2010;182:369-375.

16 Becker KA, Riethmüller J, Lüth A, Döring G, Kleuser B, Gulbins E: Acid sphingomyelinase inhibitors normalize pulmonary ceramide and inflammation in cystic fibrosis. Am J Respir Cell Mol Biol 2010;42:716724.

17 Pewzner-Jung Y, Tavakoli Tabazavareh S, Grassmé H, Becker KA, Japtok L, Steinmann J, Joseph T, Lang S, Tuemmler B, Schuchman EH, Lentsch AB, Kleuser B, Edwards MJ, Futerman AH, Gulbins E: Sphingoid long chain bases prevent lung infection by Pseudomonas aeruginosa. EMBO Mol Med 2014;6:1205-1214.

18 Brown DA, London E: Functions of lipid rafts in biological membranes. Annu Rev Cell Dev Biol 1998;14:111-136.

19 Kolesnick RN, Goñi FM, Alonso A: Compartmentalization of ceramide signaling: physical foundations and biological effects. J Cell Physiol 2000;184:285-300.

-20 Hannun YA, Obeid LM: Principles of bioactive lipid signalling: lessons from sphingolipids. Nat Rev Mol Cell Biol 2008;9:139-150.

21 Okino N, He X, Gatt S, Sandhoff K, Ito M, Schuchman EH: The reverse activity of human acid ceramidase. J Biol Chem 2003;278:29948-29953.

22 Grassmé H, Jekle A, Riehle A, Schwarz H, Berger J, Sandhoff K, Kolesnick R, Gulbins E: CD95 signaling via ceramide-rich membrane rafts. J Biol Chem 2001;276:20589-20596.

23 Nurminen TA, Holopainen JM, Zhao H, Kinnunen PK: Observation of topical catalysis by sphingomyelinase coupled to microspheres. J Am Chem Soc 2002;124:12129-12134.

24 Grassmé H, Cremesti A, Kolesnick R, Gulbins E: Ceramide-mediated clustering is required for CD95-DISC formation. Oncogene 2003;22:5457-5470.

25 Grassmé H, Jendrossek V, Riehle A, von Kürthy G, Berger J, Schwarz H, Weller M, Kolesnick R, Gulbins E: Host defense against Pseudomonas aeruginosa requires ceramide-rich membrane rafts. Nat Med 2003;9:322-330.

-26 Zhang Y, Li X, Carpinteiro A, Gulbins E: Acid sphingomyelinase amplifies redox signaling in Pseudomonas aeruginosa-induced macrophage apoptosis. J Immunol 2008;181:4247-4254.

-27 Grassmé H, Carpinteiro A, Edwards MJ, Gulbins E, Becker KA: Regulation of the inflammasome by ceramide in cystic fibrosis lungs. Cell Physiol Biochem 2014;34:45-55.

28 van Meer G, Wolthoorn J, Degroote S: The fate and function of glycosphingolipid glucosylceramide. Philos Trans R Soc Lond B Biol Sci 2003;358:869-873.

29 Schnaar RL, Suzuki A, Stanley P: Glycosphingolipids; in Varki A, Cummings RD, Esko JD, Freeze HH, Stanley P, Bertozzi CR, Hart GW, Etzler ME (eds): Essentials of Glycobiology. Cold Spring Harbor (NY), 2009.

30 D'Angelo G, Capasso S, Sticco L, Russo D: Glycosphingolipids: synthesis and functions. The FEBS J 2013;280:6338-6353.

31 Saiman L, Prince A: Pseudomonas aeruginosa pili bind to asialoGM1 which is increased on the surface of cystic fibrosis epithelial cells. The Journal of clinical investigation 1993;92:1875-1880.

-32 Dosanjh A, Lencer W, Brown D, Ausiello DA, Stow JL: Heterologous expression of delta F508 CFTR results in decreased sialylation of membrane glycoconjugates. Am J Physiol 1994;266:C360-366.

-33 Dechecchi MC, Nicolis E, Mazzi P, Cioffi F, Bezzerri V, Lampronti I, Huang S, Wiszniewski L, Gambari R, Scupoli MT, Berton G, Cabrini G: Modulators of sphingolipid metabolism reduce lung inflammation. Am J Respir Cell Mol Biol 2011;45:825-833. 


\section{Cellular Physiology Cell Physiol Biochem 2017;41:1208-1218 \begin{tabular}{ll|l} 
DOI: 10.1159/000464382 & and Biochemistry Publisned onine: 1varcn 06, 2017 & $\begin{array}{l}\text { O 2017 The Author(s). Published by S. Karger AG, Basel } \\
\text { www.karger.com/cpb }\end{array}$
\end{tabular} \\ Kovacic et al.: Glucosylceramide in Cystic Fibrosis}

34 Loberto N, Tebon M, Lampronti I, Marchetti N, Aureli M, Bassi R, Giri MG, Bezzerri V, Lovato V, Cantù C, Munari S, Cheng SH, Cavazzini A, Gambari R, Sonnino S, Cabrini G, Dechecchi MC: GBA2-encoded betaglucosidase activity is involved in the inflammatory response to Pseudomonas aeruginosa. PloS One 2014;9:e104763.

-35 Charizopoulou N, Wilke M, Dorsch M, Bot A, Jorna H, Jansen S, Stanke F, Hedrich HJ, de Jonge HR, Tümmler B: Spontaneous rescue from cystic fibrosis in a mouse model. BMC Genet 2006;7:18.

-36 Snouwaert JN, Brigman KK, Latour AM, Malouf NN, Boucher RC, Smithies O, Koller BH: An animal model for cystic fibrosis made by gene targeting. Science 1992;257:1083-1088.

-37 Tavakoli Tabazavareh S, Seitz A, Jernigan P, Sehl C, Keitsch S, Lang S, Kahl BC, Edwards M, Grassmé H, Gulbins E, Becker KA: Lack of Sphingosine Causes Susceptibility to Pulmonary Staphylococcus Aureus Infections in Cystic Fibrosis. Cell Physiol Biochem 2016;38:2094-2102.

-38 Becker KA, Henry B, Ziobro R, Tümmler B, Gulbins E, Grassmé H: Role of CD95 in pulmonary inflammation and infection in cystic fibrosis. J Mol Med (Berl) 2012;90:1011-1023.

-39 Brand M, Muller A, Alsop J, van Schaik IN, Bembi B, Hughes D: Results from a 9-year Intensive Safety Surveillance Scheme $\left(\right.$ IS $^{3}$ ) in miglustat (Zavesca ${ }^{\circ}$ )-treated patients. Pharmacoepidemiol Drug Saf 2015;24:329-333.

40 Lubamba B, Lebacq J, Lebecque P, Vanbever R, Leonard A, Wallemacq P, Leal T: Airway delivery of low-dose miglustat normalizes nasal potential difference in F508del cystic fibrosis mice. Am J Respir Crit Care Med 2009;179:1022-1028.

41 Leonard A, Lebecque P, Dingemanse J, Leal T: A randomized placebo-controlled trial of miglustat in cystic fibrosis based on nasal potential difference. J Cyst Fibros 2012;11:231-236.

42 Riethmüller J, Anthonysamy J, Serra E, Schwab M, Döring G, Gulbins E: Therapeutic efficacy and safety of amitriptyline in patients with cystic fibrosis. Cell Physiol Biochem 2009;24:65-72.

43 Nährlich L, Mainz JG, Adams C, Engel C, Herrmann G, Icheva V, Lauer J, Deppisch C, Wirth A, Unger K, Graepler-Mainka U, Hector A, Heyder S, Stern M, Döring G, Gulbins E, Riethmüller J: Therapy of CF-patients with amitriptyline and placebo - a randomised, double-blind, placebo-controlled phase IIb multicenter, cohort-study. Cell Physiol Biochem 2013;31:505-512.

44 Adams C, Icheva V, Deppisch C, Lauer J, Herrmann G, Graepler-Mainka U, Heyder S, Gulbins E, Riethmueller J. Long-Term Pulmonal Therapy of Cystic Fibrosis-Patients with Amitriptyline. Cell Physiol Biochem 2016;39:565-572.

45 Riethmüller J, Herrmann G, Graepler-Mainka U, Hellwig D, Heuer HE, Heyder S, Köster H, Kinder B, Kröger K, Paul K, Poplawska K, Melichar VO, Smaczny C, Mellies U. Sequential Inhalational Tobramycin-ColistinCombination in CF-Patients with Chronic P. Aeruginosa Colonization - an Observational Study. Cell Physiol Biochem 2016;39:1141-1151. 